\title{
O ENSINO DA PSIQUIATRIA E O PODER DISCIPLINAR DA ENFERMAGEM RELIGIOSA: O HOSPÍCIO DE PEDRO II NO SEGUNDO REINADO
}

\author{
Maria Angélica de Almeida Peres ${ }^{1}$, Ieda de Alencar Barreira², Tânia Cristina Franco Santos ${ }^{3}$, Antonio José de \\ Almeida Filho ${ }^{4}$, Alexandre Barbosa de Oliveira ${ }^{5}$
}

\footnotetext{
${ }^{1}$ Doutora em Enfermagem. Professora da Escola de Enfermagem Anna Nery (EEAN) da Universidade Federal do Rio de Janeiro (UFRJ). Rio de Janeiro, Brasil. E-mail: aguaonda@uol.com.br

${ }^{2}$ Doutora em Enfermagem. Professora do Programa de Pós-Graduação da EEAN/UFRJ. Bolsista CNPq. Rio de Janeiro, Brasil. E-mail: iedabarreira@openlink.com.br

${ }^{3}$ Doutora em Enfermagem. Professora da EEAN/UFRJ. Bolsista do CNPq. Rio de Janeiro, Brasil. E-mail: taniacristinafsc@terra. com.br

${ }^{4}$ Doutor em Enfermagem. Professor da EEAN/UFRJ. Rio de Janeiro, Brasil. E-mail: ajafilhos@gmail.com

${ }^{5}$ Doutorando do Programa de Pós-graduação em Enfermagem da EEAN/UFRJ. Rio de Janeiro, Brasil. E-mail: alexbaroli@ yahoo.com.br
}

RESUMO: O estudo tem como objetivos descrever as relações entre o ensino de psiquiatria e o poder disciplinar das Irmãs de Caridade no Hospício de Pedro II, analisar as circunstâncias em que se deu o concurso que elegeu o primeiro Catedrático de Psiquiatria da Faculdade de Medicina do Rio de Janeiro e discutir suas repercussões para o poder disciplinar das Irmãs de Caridade no Hospicio. Estudo histórico documental, que analisa livros administrativos da Santa Casa de Misericórdia e artigos do Jornal do Commércio, com base no referencial foucaultiano. O concurso para catedrático de psiquiatria, embora amplamente questionado na imprensa, elegeu um médico que se opunha frontalmente à administração do Hospício pela Santa Casa. Ao ser admitido como Diretor Sanitário do Hospício, esse catedrático iniciou uma reforma administrativa, levando à progressiva redução da atuação religiosa e consequente declínio da assistência de enfermagem naquele espaço, possibilitando sua medicalização.

DESCRITORES: Enfermagem. História da enfermagem. Enfermagem psiquiátrica.

\section{TEACHING PSYCHIATRY AND THE DISCIPLINARY POWER OF RELIGIOUS NURSING: HOSPICE PEDRO II DURING THE SECOND REIGN}

\begin{abstract}
The objectives of this study are to describe the relationship between teaching psychiatry and the disciplinary power of the Sisters of Charity from the Hospicio de Pedro II; to analyze the circumstances in which the contest to appoint the first Professor of Psychiatry at the Faculdade de Medicina do Rio de Janeiro, Brasil took place. This is a documentary historical research that analyzes the administrative books of the Santa Casa da Misericórdia and articles from the "Iornal do Commercio" based on the Michel Foucault framework. The selection for the first Professor of Psychiatry, although widely questioned by the press, elected a physician who opposed the institution's management. Upon admission as the Hospice's Sanitary Director, this professor initiated an administrative reform, leading to the progressive reduction of the sisters of charity's activities and consequently, nursing care within that arena, allowing its medicalization.
\end{abstract}

DESCRIPTORS Nursing. History of nursing. Psychiatric nursing.

\section{LA ENSEÑANZA DE LA PSIQUIATRÍA Y EL PODER DISCIPLINAR DE LA ENFERMERÍA RELIGIOSA: EL HOSPICIO DE PEDRO II EN EL SEGUNDO REINADO}

RESUMEN: El estudio tiene como objetivos: describir las relaciones entre la enseñanza de la psiquiatría y el poder disciplinar de las Hermanas de la Caridad del Hospicio de Pedro II; analizar las circunstancias en que se realizó el concurso que eligió el primer Catedrático de Psiquiatría de la Facultad de Medicina de Rio de Janeiro; discutir las repercusiones para el poder disciplinar ejercido por las Hermanas de la Caridad del Hospicio de Pedro II. Es un estudio de carácter histórico y documental en el que se analizan libros administrativos de la Santa Casa de Misericordia y los artículos del Jornal do Comércio, con base en el referencial foucaultiano. El concurso para Catedrático de Psiquiatría, aunque duramente cuestionado por la prensa, eligió un médico opositor a la administración del Hospicio de Pedro II por la Santa Casa de Misericordia. Tras su ingreso como director del hospicio, ese catedrático comenzó una reforma administrativa, lo que lleva a la progresiva reducción de la actividad religiosa y la consiguiente reducción de los cuidados de enfermería en ese espacio, lo que permite su medicalización.

DESCRIPTORES: Enfermería. Historia de la enfermería. Enfermería psiquiátrica. 


\section{INTRODUÇÃO}

O estudo trata do primeiro concurso para a Cadeira de Psiquiatria da Faculdade de Medicina do Rio de Janeiro (FMRJ) e suas implicações para o poder disciplinar das Irmãs de Caridade no Hospício de Pedro II (HPII). O contexto históricosocial é o do Brasil Império, durante o segundo reinado de D. Pedro II. A partir de meados do século XIX, a manutenção da "ordem" adquire uma conotação mais complexa, assumindo a feição de uma monarquia parlamentar, de cunho centralizador, baseada em uma economia agrárioexportadora, firmada em um projeto civilizador, que supunha a supressão gradual da escravidão.

Criado em 1841, como instituição anexa à Santa Casa de Misericórdia (SCM) do Rio de Janeiro, o HPII passa a funcionar em 1852, sob a orientação da Igreja Católica, através da Irmandade da Misericórdia, da Congregação das Filhas da Caridade de São Vicente de Paulo e do Estado Imperial. As divergências entre os documentos legais do HPII e a prática institucional mostram que as Irmãs de Caridade, trazidas da França para o Brasil para atuarem como enfermeiras, exerciam o controle administrativo do hospício, apoiadas pelo discurso filantrópico da SCM, que tinha nas religiosas servidoras diligentes e fiéis executoras da disciplina em seu favor e não em favor dos médicos. ${ }^{1-2}$

O hospício era organizado em quatro serviços: o administrativo, o sanitário (enfermarias, farmácia e oficinas de trabalho para os doentes), o econômico (lavanderia, rouparia e refeitório) e o religioso (capela). O Regimento Interno mantinha as Irmãs de Caridade em todos esses serviços, sendo que a Irmã Superiora dirigia o serviço econômico e as enfermarias, estando na mesma ordem hierárquica que o médico diretor do serviço sanitário, deixando-o com a direção parcial do mesmo. ${ }^{3}$

Esta situação era objeto de crítica dos médicos que denunciavam a má administração do único hospício do país nas mãos de uma instituição filantrópica e não do governo. João Carlos Teixeira Brandão, um alienista renomado e politicamente articulado, responsabilizava as Irmãs de Caridade e os enfermeiros por maus tratos inflingidos aos doentes. Os exercentes de enfermagem eram orientados pelas Irmãs, tendo como referência a paciência, a caridade e a manutenção da ordem pelo uso de medidas disciplinares, sempre que julgadas úteis para o tratamento, propiciando seu uso punitivo. Os médicos afirmavam que o descontrole administrativo da instituição, incluindo a decisão sobre as internações e altas, inviabilizava o tratamento moral dos doentes mentais. ${ }^{3-4}$

Nas últimas décadas do século XIX, no momento de transição da Monarquia para a República, ganha força na sociedade o pensamento positivista que valorizava o saber médico como útil ao projeto políticosocial do Estado. Neste contexto, os médicos alienistas se colocaram na linha de frente na luta pelo poder no HPII.

A criação da Cadeira de Moléstias Mentais, nas faculdades de medicina do país, em 1882, representou um avanço na prática alienista, que adquiriu status de especialidade médica, passando a ser denominada psiquiatria. A criação da nova Cadeira aumentava a necessidade de um campo prático para o avanço da ciência médica, dependente do controle dos corpos nos espaços. Assim, para o meio acadêmico era crucial que os médicos (ou a Faculdade de Medicina) exercessem o poder disciplinar no campo prático, no caso, o HPII, onde imperava a disciplina religiosa, controlada pelas Irmãs de Caridade. ${ }^{3-5}$

Os objetivos deste estudo são: descrever as relações entre o ensino de psiquiatria e o poder disciplinar das Irmãs de Caridade no HPII, analisar as circunstâncias em que se deu o concurso que elegeu o primeiro Catedrático de Psiquiatria da Faculdade de Medicina do Rio de Janeiro e discutir as repercussões da criação da Cadeira de Psiquiatria para o poder disciplinar exercido pelas Irmãs de Caridade no HPII.

Esse estudo se justifica pela ausência de pesquisas que detalhem as circunstâncias da ocupação da $1^{\text {a }}$ Cadeira de Psiquiatria da Faculdade de Medicina da Corte, fato que foi determinante para a saída das Irmãs de Caridade do HPII, e por tratar do período pré-profissional da enfermagem, ainda pouco explorado pelos grupos que se dedicam à pesquisa da História da Enfermagem Brasileira, onde se evidencia a influência das ordens religiosas.

\section{METODOLOGIA}

Estudo qualitativo de natureza documental, cujas fontes primárias foram os seguintes docu-

\footnotetext{
* Embora esta instituição seja referenciada em alguns documentos como Hospício Dom Pedro II e Hospício Pedro II, o decreto n. 82, de 18 de julho de 1841, funda um hospital destinado privativamente para tratamento de alienados, com a denominação de Hospício de Pedro II.
} 
mentos pertencentes à SCM/RJ: livro "Portarias e Atos do Provedor (1884-1890)" e livro “Actas e Termos das sessões e deliberações da administração da Santa Casa de Misericórdia do Rio de Janeiro-1881-1890", onde se encontram as "Atas das Sessões de Mesa e Junta", os "Relatórios da Provedoria" e o "Relatório Anual da Direção Sanitária do HPII". Também foram utilizados artigos do "Jornal do Commércio", acessados no acervo microfilmado da Biblioteca Nacional. A coleta de dados ocorreu durante todo o ano de 2008. Os documentos foram descritos em um quadro de análise, de acordo com sua cronologia, autoria e temática, sendo os mesmos submetidos à crítica interna e externa e inseridos em seu contexto histórico-social, possibilitando a sua interpretação. Nas citações diretas das fontes primárias foi mantida a grafia da época. Subsidiou a análise dos dados o referencial foucaultiano sobre poder e as tecnologias disciplinares, uma vez que o cenário de estudo é uma instituição psiquiátrica, onde o controle dos corpos estava em jogo e onde dois grupos, com seus diferentes saberes/poderes, se enfrentavam. Os estudos de Michel Foucault propiciam a compreensão dos nexos entre a prática da enfermagem, com seus mecanismos disciplinares e as relações de poder, especialmente da concepção de poder em rede e micropoder. ${ }^{6}$ Esta pesquisa foi aprovada pelo Comitê de Ética da EEAN-HESFA/UFRJ em 28 de março de 2007 (Protocolo n ${ }^{\circ}$ 022/07).

\section{RESULTADOS E DISCUSSÃO}

\section{O ensino da Psiquiatria e o poder disciplinar das Irmãs de Caridade no HPII}

Durante quase cinquenta anos, os docentes da Cadeira de Medicina Legal, ministraram nas Faculdades de Medicina, os ensinamentos sobre psiquiatria. ${ }^{5-7}$ No Rio de Janeiro, antes da criação da cadeira de psiquiatria, tal conteúdo era ministrado por Nuno de Andrade, que se tornou regente interino desta cadeira, em 1881. Este médico passou a utilizar uma sala no HPII, mediante autorização da SCM, contida em ofício de 12/08/1881 e, desde logo, considerou o seu exercício docente prejudicado: "Se hoje [...] vejo a minha autoridade de clínico tolhida pelas attribuições conferidas às Irmãs de Caridade [...], o que será do dia de amanhã, quando a necessidade do ensino crear-me novas imposições e mais graves encargos?" 8:5 Nesta fala percebe-se a utilização a disciplina no HPII pelas religiosas e a resistência médica, o que vai ao encontro do caráter relacional do poder, em que as lutas contra o seu exercício são feitas dentro da própria teia de poder. ${ }^{9}$

Em fevereiro de 1883 ocorreu um embate entre a Faculdade de Medicina e a SCM, quando o diretor da Faculdade encaminhou um pedido de ampliação do espaço cedido à faculdade no Hospital Geral da SCM e no HPII. O diretor afirmava que, para tanto, o Estado arcaria com um auxílio pecuniário à SCM e também levantava a possibilidade desta entregar à Direção da Faculdade ou do Governo todas as enfermarias utilizadas para o ensino no Hospital, sem se encarregar senão do fornecimento das dietas e remédios, mediante uma contribuição anual. ${ }^{10}$

O diretor da Faculdade de Medicina assegurava ainda que os professores médicos ficariam sujeitos ao regulamento do serviço sanitário dos Hospitais da SCM. No entanto, previa que o funcionamento do HPII teria que ser alterado, modificando-se os horários de entrada e saída de professores e alunos nas enfermarias, estipulados pela Irmã Superiora, responsável pelas chaves do hospício. O diretor afirmava que a visita dos alunos não iria interferir nos horários da alimentação e medicação dos doentes, que eram atribuições das Irmãs de Caridade e de seus ajudantes nas enfermarias.

Na solicitação da Faculdade de Medicina nota-se a intenção em modificar a rígida disciplina imposta pelas religiosas, no que tange à circulação de visitantes na instituição, em favor do ensino médico. O saber na ótica foucaultiana é considerado espaço em que o sujeito pode tomar posição para falar dos objetos de que se ocupa em seu discurso, neste sentido o saber da medicina clínica é o conjunto de funções de observação, interrogação, decifração, registro, decisão, que podem ser exercidas pelo sujeito do discurso médico. ${ }^{11}$

Tal proposta foi entendida pelo Provedor da SCM como uma intromissão, que infringia o dogma sagrado da instituição, que era a caridade: "O que falta mais para que a direcção do serviço sanitário fique commetida á Faculdade de Medicina? [...] Onde ficará essa sujeição aos regulamentos do serviço sanitário do Hospital, quando fica elle todo alterado, e quando os lentes [professores] de clinica na parte disciplinar estão inteiramente independentes da Administração da Santa Casa?". 10:3

No discurso do Provedor nota-se a intenção de impedir o exercício do poder médico no HPII, o que movia a luta médica para retirar sua adminis- 
tração da SCM, possibilitando uma transformação nas práticas asilares em favor do ensino de psiquiatria. O conceito de transformação foi associado por Foucault ao conceito de ruptura, pois só acontece, através da superação de obstáculos que levam a reorganização de saberes, o que implica em um novo olhar, novo conceito, uma nova prática. ${ }^{11}$

Para reforçar sua opinião, o Provedor solicitou ao Diretor Sanitário do Hospital Geral e ao Diretor Sanitário do HPII, a posição dos respectivos corpos clínicos sobre tal proposta. O Diretor Sanitário do Hospital Geral, Barão do Lavradio, declarou opor-se à concessão das enfermarias solicitadas pela Faculdade naquele hospital. Em relação à clínica psiquiátrica ele sugeriu que o governo autorizasse a Faculdade a construir duas enfermarias para a clínica psiquiátrica no "Asylo de Mendigos, aproveitando para isso grande numero de indivíduos privados da razão que alli existem e existirão, porque não podem ser transferidos para o Hospicio de Pedro II por falta de lugares [...]". 10:3

A posição do então Diretor Sanitário do HPII, Agostinho José de Souza Lima, era delicada, uma vez que ocupava o cargo de lente interino da cadeira de psiquiatria e também era membro da Comissão que elaborou a proposta feita à SCM. Em sua resposta ao Provedor, julgando ser possível conciliar os interesses recíprocos da Faculdade e do HPII, lembra que a nova disciplina, por pertencer ao último ano do ensino médico, contaria com um reduzido número de alunos e que a visita destes deveria ocorrer apenas aos domingos. Entretanto, sendo o domingo dia ordinário de visitas, para diminuir os inconvenientes da presença dos alunos nas enfermarias, coloca ele ainda as seguintes sugestões: " $1^{\circ} \mathrm{A}$ visita clinica será admittida somente na secção dos homens, salvo um ou outro caso mais importante do outro sexo, julgado a critério do respectivo médico e do director, e cuja apresentação aos alumnos n'uma sala especial, possa ser completamente indifferente á alienada. $2^{\circ} \mathrm{Na}$ secção dos homens mesmo não será toda ella percorrida por todos os alumnos, senão somente a parte do fundo contígua ás casas fortes, para onde podem elles entrar directamente; e para onde poderão ser conduzidos outros alienados dignos de serem objectos de estudo clinico, alem dos que lá existem". ${ }^{10: 4}$

Nas palavras do diretor do Serviço Sanitário do HPII podemos observar a dificuldade dos alunos de medicina em transitarem pelas enfermarias, principalmente aos domingos, dias de visita e dia reservado ao culto cristão. Na rotina do hospício estava incluída a missa dominical com participação das Irmãs, dos alienados e dos visitantes. Por outro lado, o trânsito pela enfermaria masculina era mais fácil, uma vez que nela atuavam somente ajudantes de enfermaria homens, diferentemente da enfermaria feminina, onde eram ajudantes de enfermaria as meninas órfãs da SCM e as Irmãs de Caridade, o que levava a uma restrição maior à entrada de homens. ${ }^{3}$

Todos os trabalhadores do HPII (médicos, irmãs de caridade, ajudantes de enfermarias, guardas e serventes) eram submetidos a um rigoroso controle de cumprimento de tarefas e horários em um sistema de vigilância, onde uns controlam os outros, numa escala hierárquica que Foucault denominou de pirâmide de olhares. ${ }^{12}$

O Provedor da SCM, em sessão da Mesa e Junta, apresentou a proposta da Faculdade de Medicina e informou que o corpo médico do Hospital Geral opunha-se à concessão das enfermarias no Hospital Geral e que o corpo médico do HPII julgava inconveniente a clínica da faculdade na instituição e só a admitiria com as restrições impostas. Sendo assim, a Mesa e Junta apóiam o parecer dos Diretores Sanitários e consideram inadmissível a proposta da Faculdade de Medicina, nos termos em que se achava formulada. ${ }^{10}$

Dessa forma, a SCM impunha o regime disciplinar de seus hospitais à Faculdade de Medicina, com desvantagem para o ensino médico. A resistência em permitir o ensino clínico era maior no HPII do que no Hospital Geral, onde o diretor-médico tinha poder de mando sobre o tratamento. ${ }^{2}$ Ao contrário, no HPII cabia à Irmã Superiora o controle do regime interno das enfermarias e o pessoal de enfermagem era capaz de conduzir o tratamento, que era pautado no controle dos corpos, não interessando, portanto, aumentar a presença de médicos naquele espaço. ${ }^{3}$

\section{A Cadeira de Psiquiatria da Faculdade de Medicina do Rio de Janeiro}

Ainda em decorrência da Reforma Leôncio de Carvalho, ocorrida em 1879, mas que nem todas as disposições haviam sido executadas, foram sancionados os decretos $n^{\circ} 8.024 / 1881$, que mandava executar os regulamentos dos exames das Faculdades de Medicina do Império e no 3.141/1882, que aumentava o número de disciplinas do curso médico com a incorporação de sete cadeiras, entre elas a "Cadeira de Moléstias Mentais. O reconhecimento da psiquiatria como uma especialidade, ao 
distingui-la como um campo do saber e da prática médicos, constituiu novas relações de poder na sociedade" $8: 13$

Assim, com base no decreto 8024/1881, a Faculdade de Medicina do Rio de Janeiro determinou a realização de concurso público para a Cadeira de Moléstias Mentais, que embora tivesse na legislação esta nomenclatura, era denominada pelos alienistas de "Cadeira da Clínica Psiquiátrica" ou "Cadeira de Psiquiatria". O lugar de lente da Cadeira de Psiquiatria daria aos alienistas um poder com "garantias e justificações nos privilégios do conhecimento, onde o médico detém um saber científico, que fundamenta a sua intervenção e a sua decisão. ${ }^{14}$

Em 1883 foram abertas as inscrições para o concurso à clínica psiquiátrica. Cinco médicos se apresentaram para concorrer à vaga: Belisário Augusto Soares de Souza, Domingos Jacy Monteiro Junior, João Carlos Teixeira Brandão, João Ferreira de Campos e José Eduardo Teixeira de Souza. Este último, em meio ao processo, desistiu de prestar o concurso. ${ }^{15}$

A "Nova Cadeira", considerada um avanço no ensino médico brasileiro, foi para os alienistas motivo de dissidências, acirradas com o início das provas em fevereiro de 1883 e, até abril deste ano, o espaço público desta contenda foi a seção de "Publicações a Pedido" do Jornal do Commércio, o jornal de maior circulação do Império.

Dessa forma, no dia 17 de fevereiro de 1883 , Manoel Joaquim Fernandes Eiras, ilustre alienista, destacava que "Esta criação, já há muito reclamada, é um dos maiores beneffícios prestados à sciência e ao Paíz. [...] nada há mais importante, que reclame estudo tão atturado e observação minuciosa, do que as affecções mentaes [...]". E que, "é no terreno da prática, da observação diaria, diante da multiplicidade das formas da loucura, que se deve exercer o ensino da cadeira de psychiatria. Tudo o mais é poesia". 16:2

Tal afirmação nos remete ao saber científico definido por Foucault, como aquele que organiza o espaço, as relações e o fazer no hospital, orientando-o para a intervenção sobre o corpo do doente e funciona, ao mesmo tempo, como instância de produção de saber e, também, de formação profissional e de transmissão desse saber..$^{8-11}$

No dia seguinte, já iniciado o processo de seleção, Eiras apontava a escassez de médicos interessados nessa especialidade e opinava também que os candidatos não tinham preparo suficiente para serem professores de psiquiatria, alegando que "para exercer a cadeira de psychiatria, de accordo com os progressos da sciência [...] é preciso confessar que não há ninguém habilitado. É necessário recorrer a uma celebridade européia" . 16:2

O candidato Ferreira de Campos se manifestou contra a contratação de um alienista europeu e se dirigiu à Eiras em tom irônico: "O Sr. Dr. Eiras em momento de lazer afirmou que não havia no Brazil quem tivesse habilittações para ser professor de clínica psychiatrica, não attendendo sequer aos nomes de cinco candidatos, que propõe-se a reger essa cadeira, dando em concurso prova das habilittações que supõem ter. [...] Foi inconsiderado e injusto". ${ }^{17: 2}$

Cada alienista representava um grupo diferente e a defesa por um alienista estrangeiro ou brasileiro para ocupar a Cadeira de Psiquiatria pode ser entendida pelas questões relacionadas por Foucault ${ }^{12}$ à medicina, à psiquiatria, à economia, ao hospital, etc, tendo como questão central o poder e sua difusão no corpo social, seu exercício em instituições, sua relação com a produção da verdade, bem como as resistências que ele suscita.

O concurso foi realizado em quatro etapas, a saber: 1) Prova oral com sorteio de ponto e preparo em 24 horas; 2) Prova prática de histologia e química biológica; 3) Prova clínica; 4) Prova oral de improviso, com sorteio de ponto. Quinze Lentes da Faculdade de Medicina participaram da votação para classificar os candidatos, no dia 11 de abril. A lista de classificação, para nomeação pelo Governo Imperial, ficou assim composta: $1^{\circ}$ lugar João Carlos Teixeira Brandão (oito votos); $2^{\circ}$ lugar Belisário Augusto Soares de Souza (quatro votos); $3^{\circ}$ lugar Domingos Jacy Monteiro (três votos). O candidato João Ferreira de Campos foi excluído da classificação por não ter obtido voto. ${ }^{15}$

A vitória de Teixeira Brandão foi contestada no dia seguinte da proclamação dos resultados, com base na denúncia das seguintes irregularidades: a) ter feito parte de uma das comissões e ter dado parecer sobre uma das provas, um dos lentes recém-nomeados, que não podia tomar parte em ato algum de concurso e que era amigo íntimo do candidato classificado em primeiro lugar; b) que haviam feito parte da banca três lentes empregados na clínica de saúde do candidato em questão, sendo um deles compadre e protetor do mesmo; c) que este candidato não havia completado o tempo regulamentar em nenhuma das provas; $\mathrm{e}$, que sua prova escrita era inferior a dos demais concorrentes. ${ }^{18}$

Os alienistas apelavam ao espírito de justiça do Imperador alegando que, um conluio teria sido 
armado para que Teixeira Brandão ganhasse o concurso. ${ }^{18}$ Ocorre então uma série de comentários férreos sobre o concurso, como este assinado sob o pseudônimo de "Porco em pé", publicado no dia 13 de abril, que questiona a capacidade científica de Teixeira Brandão e sugere a sua renúncia:

"Não há um médico, um estudante, não há ninguém que tendo assistido, com a calma que traduz a veracidade de um juízo imparcial, ao concurso da clínica psychiatrica, não murmure consigo mesmo, ou em expansões públicas, a surpreza de que se acham tomados pela votação anômala que collocou em primeiro lugar àquelle que melhor fora resignar a cadeira, porquanto a falta de prestígio scientífico não lhe dará ouvintes" e testemunha que o candidato "quer na prova oral, quer na prova de improviso, foi o único que falou apenas meia hora, sem voz, sem sciência e sem palavra" . 19:2

A repercussão da contenda foi de tal monta que o Imperador em pessoa se comprometeu a ler as provas. Entretanto um novo fato é denunciado na imprensa, no dia 17 de abril:

“Está no domínio público que o Dr. Teixeira Brandão, sob pretexto de que sua prova escrita está mal paginada [...], ofereceu-se a dittar a um empregado da secretaria uma cópia com destino ao governo, e fê-lo, mas tão fielmente sahio adulterada do original que o digno Sr. Secretário recusou-se a referendá-la. O conselheiro director, intervindo, resolveu o incidente mandando subir cópia e original. Pede-se a S.M. o Imperador que tome o trabalho de confrontar esta àquella". 20:2

A disputa médica pela cadeira de psiquiatria pautava-se na desqualificação do saber do candidato classificado em primeiro lugar, como forma de não permitir que o mesmo tomasse posse, revestindo-se do poder conferido ao cargo de catedrático, uma vez que o conhecimento sempre tem um propósito: se caracteriza pela vontade de dominar ou apropriar, além disso, ele é buscado por sua utilidade, é potente e instável. ${ }^{11}$ Além disso, nos processos de disciplinarização dos hospitais, se destaca a distribuição dos indivíduos no espaço. ${ }^{9}$

A despeito dos protestos de seus opositores, em 25 de abril de 1883 Teixeira Brandão toma posse como o primeiro professor de psiquiatria do Brasil, após trinta anos da inauguração do HPII, marcando o momento em que a medicina mental, deixando de pertencer à cadeira de Medicina Legal, obtém status de disciplina médica independente na Faculdade de Medicina. ${ }^{3}$

\section{A Cadeira de Psiquiatria afeta o poder disciplinar das Irmãs de Caridade no HPII}

A necessidade da psiquiatria se constituir como especialidade levava a disputas nos espaços acadêmico/científico e assistencial. Para Foucault $^{12}$, saber e poder estão diretamente relacionados, pois não há relação de poder sem constituição de um campo de saber, bem como todo saber constitui novas relações de poder. Logo, a criação da Cadeira de Psiquiatria trouxe à tona novos embates. Mesmo havendo dois grupos de médicos que concorriam pela ocupação desses espaços institucionais, tais grupos tinham como ponto em comum a oposição à administração do HPII pela SCM e ao poder por ela conferido às Irmãs de Caridade.

Desde a criação da Cadeira de Psiquiatria em 1882, os alienistas se aproximavam de um confronto com o poder religioso, tendo como principal alvo a SCM. Neste sentido, o Dr. Eiras coloca-se como porta-voz da classe médica, ao se referir ao fato de a SCM ter exonerado do cargo de diretor sanitário do HPII, o professor da Faculdade de Medicina, Nuno de Andrade, após ter ele proposto a separação do HPII da SCM, argumentando que sua autoridade de clínico era tolhida pelas atribuições conferidas às Irmãs de Caridade. ${ }^{16}$

Dois dias depois comentava ele, com indignação, o excesso de poder concedido às Irmãs de Caridade pela SCM, considerado um entrave ao exercício da medicina: "O poder que ellas [Irmãs de Caridade] se achão revestidas excede mesmo aos princíppios de sua comunidade [...]. Seja-nos permittido, neste momento, lamentar, que as provedorias da Santa Casa de Misericórdia, exercidas até hoje pelos mais abalisados jurisconsultos, homens de estado, ora no exercício do poder executivo, ora no legislativo, tenham deixado no esquecimento e abandono, matéria de tanta importância e de sua especial comppetência". 17:2

Na segunda metade do século XIX, as denúncias contra o poder religioso nas instituições de saúde eram parte de uma estratégia por maior poder da medicina, que nesse momento tem que se defrontar com outras instituições ou outras instâncias sociais, para impor o modelo teórico psiquiátrico no hospício. ${ }^{7}$

Os médicos apontavam para a importância da criação de leis para a organização dos asilos no Brasil e para a transformação da realidade do HPII, fixando inclusive a área de atuação, tanto dos médicos, como das Irmãs de Caridade: 
“O médico não está fora do alcance daquelle poder [da legislação], a sua responsabilidade é effectiva, assim como os seus conselhos e a sua sciência são respeitados. As Irmãs de Caridade também têm a sua esfera de ação, sem que por isso percam a autoridade a que suas virttudes e abnegação dão direito. As que exercem tão digno mister no Hospício de Pedro II difficilmente poderão ser substituídas em nossa terra; elas serão as primeiras a prestar homenagem à lei, porque foram assim educadas em seu paíz, onde aquella é uma realidade" ${ }^{16: 2}$

Na citação acima, destaca-se a obediência das religiosas como qualidade, no entanto, seus saberes eram questionados e desvalorizados porque representavam o saber como materialidade, como prática, como acontecimento, que se formara a partir das práticas políticas disciplinares exercidas pelas Irmãs de Caridade, mas que de agora em diante deveriam ser exercidas pelos médicos e denominadas como ciência. ${ }^{7}$

Além disso, declarava que apesar das impressionantes instalações físicas do HPII, as diretrizes emanadas da SCM não permitiam que ele se constituísse como espaço da produção de saber médico psiquiátrico, não obstante os esforços dos diretores sanitários e dos facultativos clínicos por uma reforma: "É indispensável a organização de um plano de reformas, para que elle [o HPII] possa melhor funcionar e atender as últimas experiências científicas. [...] aquelles que ousaram ir de encontro aos interesses da Santa Casa, forão todos exonerados" . 16:2 $^{2}$

No entanto, a existência de uma autoridade acadêmica em psiquiatria levou a uma mudança da forma como a SCM tratava os médicos desta especialidade, uma vez que a mesma ganhou reconhecimento social. Tanto assim que, em 24 de outubro de 1884, um ano e meio depois de tomar posse na Faculdade de Medicina, Teixeira Brandão foi nomeado pelo provedor da SCM, Barão de Cotegipe, como médico do HPII. ${ }^{3}$

O encontro do catedrático de psiquiatria com as Irmãs de Caridade no espaço do HPII acelera o embate crescente entre o saber-poder religioso e o científico. De um lado, o discurso caritativo-religioso justificava o domínio da igreja nas instituições hospitalares, mas de outro, o discurso médico buscava transformar a medicina mental em prática científica, com um mandato social de controle de sujeitos sociais desviantes. O propósito desse grupo de médicos vai se concretizar na luta pela desanexação do HPII da SCM.
Em 1886, Teixeira Brandão publicou o relatório "Os alienados no Brazil", onde seguiu a mesma linha de ataque à administração do HPII adotada anteriormente por Nuno de Andrade e que causara sua exoneração do cargo de diretor sanitário do HPII. Diferentemente, Teixeira Brandão não foi retaliado pelo Provedor, apesar dos evidentes contrastes entre as posições políticas de Teixeira Brandão e a do Barão de Cotegipe: o primeiro era um militante republicano e anticlerical, enquanto o segundo era presidente do Conselho de Ministros do gabinete conservador e provedor da SCM. Não obstante tais diferenças, Teixeira Brandão teve várias de suas solicitações atendidas pela SCM. Comentários apontaram que o Barão de Cotegipe tinha Teixeira Brandão como seu protegido político, justificando o apoio do provedor às atitudes do médico no HPII, apesar dos possíveis prejuízos que poderia trazer a SCM. ${ }^{3,22}$

Com a autoridade conferida pela posição de catedrático, Teixeira Brandão investe no movimento de medicalização do louco, que caracteriza a função dos psiquiatras do século XIX, que "criticam a insuficiência e ineficácia do hospício, mostrando a necessidade de multiplicação de instituições articuladas, amparadas por uma lei, que desse aos hospícios a exclusividade de seqüestração do louco e regulasse a sua situação na sociedade". 22:96

Em 21 de fevereiro de 1887, Teixeira Brandão foi nomeado Diretor do Serviço Sanitário do HPII. ${ }^{21}$ Sete meses depois, foram aprovadas as novas "Instruções para o Serviço Sanitário do HPII", que determinava alterações no Regimento Interno, onde as principais mudanças foram a distribuição dos doentes por categorias médicas, de modo a possibilitar o tratamento moral, segundo o modelo francês, e a colocação do Diretor-Médico, no comando do serviço sanitário, anteriormente confiado às Irmãs de Caridade. ${ }^{3}$

Atendendo às queixas de Teixeira Brandão, quanto à interferência das Irmãs de Caridade no serviço sanitário do HPII, as Instruções de 1887 determinaram a retirada das religiosas do mesmo, mantendo-as apenas na ala feminina, e também o aumento do número de médicos, a indicação dos médicos pelo diretor e a subordinação dos enfermeiros, ajudantes e serventes aos médicos na ala masculina. Assim, os médicos passam a exercer a vigilância hierárquica, que é um instrumento de controle disciplinar, que implica em vigiar contínua e permanentemente os indivíduos, submetendo-os a uma pirâmide hierarquizada de olhares. ${ }^{12}$ 
A influência do relatório do catedrático de psiquiatria nas Instruções de 1887 também é percebida na reforma do serviço médico, a qual ensejou a ampliação das práticas técnico-científicas e dos espaços de ensino e pesquisa, com a criação dos gabinetes eletroterápico, de análise histoquímica e anátomopatológico e com a implantação de registros sobre a doença e o tratamento ${ }^{3}$, reforçando o saber/poder médicos, através da tecnologia disciplinar do exame, na qual o indivíduo passa a ser, ao mesmo tempo, efeito e objeto do poder e do saber. ${ }^{9}$ Ao tratar da inversão hierárquica no hospital para a ampliação do poder médico, Foucault ressalta que neste momento aparece uma série de anotações que acumulam e transmitem informações, fazendo do hospital um lugar de registro, acúmulo e formação de saber. ${ }^{14}$

As novas normas institucionais respaldavam o diretor sanitário do HPII, favorecendo a gestão de Teixeira Brandão no sentido da inversão do exercício de poder no HPII, através do processo normalizador da medicina.

Dessa forma, ocorre uma ruptura na organização de um modelo religioso de enfermagem psiquiátrica que, aos poucos vai sendo substituido por uma modelo leigo, que desqualifica a assistência ao doente mental, uma vez que, a enfermagem à época, era exercida por qualquer pessoa que desejasse praticá-la, não havendo exigência de alfabetização ou formação mínima ${ }^{3}$. O que distinguia as Irmãs dos demais exercentes era a formação escolar das mesmas e o preparo em hospitais franceses, permitindo um posicionamento não subordinado aos médicos, que precisou ser neutralizado para que ocorresse o avanço no processo de medicalização do espaço psiquiátrico.

\section{CONSIDERAÇÕES FINAIS}

A realização dessa pesquisa colocou-nos diante de dificuldades de diversas naturezas. Além das poucas referências bibliográficas publicadas por enfermeiros sobre o tema, o maior desses óbices foi a má conservação e o difícil acesso ao acervo da Santa Casa de Misericórdia do Rio de Janeiro. Não obstante, a conservação adequada dos documentos e a disponibilidade de acesso nos acervos da Biblioteca Nacional, do Instituto Histórico e Geográfico Brasileiro e do Arquivo Nacional permitiram a realização deste estudo. Também se destaca o trabalho da imprensa no século XIX, que publicava cópia de relatórios, cartas e ofícios da época, criando um acervo paralelo ao original, que se encontra microfilmado na seção de periódicos da Biblioteca Nacional.

Os resultados da pesquisa nos permitiram concluir que a criação do primeiro hospício do país possibilitou a existência de um campo prático para o tratamento e o ensino das doenças mentais. O fato do HPII ser administrado pela SCM fez dele palco de disputas entre as Irmãs de Caridade e os médicos, voltadas para o controle dos corpos na instituição asilar, porém envolvendo interesses distintos. As Irmãs de Caridade detinham um poder disciplinar por elas implantado desde a criação do HPII, visando demonstrar para a sociedade o aspecto caritativo e filantrópico característico das instituições pertencentes à SCM, enquanto que os médicos e professores da Faculdade de Medicina do Rio de Janeiro almejavam ampliar o poder decorrente dos seus saberes e práticas, pautados no controle dos corpos.

A admissão do catedrático de psiquiatria como médico do hospício, a despeito das críticas sobre a lisura do concurso para a Cadeira de Moléstias Mentais, demarca a efetiva ascensão dos alienistas no HPII, consolidada pela nomeação de Teixeira Brandão, como Diretor Sanitário do estabelecimento, três anos depois, com a disposição de promover uma reforma, que atendesse as exigências da prática alienista.

A ampliação da atuação médica sobre a internação e alta dos alienados, bem como sobre a prescrição do tratamento psiquiátrico e comando dos ajudantes de enfermarias na ala masculina, resultaram da força política de Teixeira Brandão, que em 1890, já no período republicano, foi nomeado o primeiro diretor da recém-criada Assistência Médica e Legal de Alienados, que ficou responsável pela administração do hospício, que no mesmo ano foi desanexado da SCM. Essas transformações foram fundamentais para o declínio do poder das Irmãs de Caridade no HPII, a partir da progressiva redução da atuação religiosa nos serviços sanitário e administrativo e conseqüente declínio da assistência de enfermagem, evidenciado pela saída das Irmãs de Caridade do espaço psiquiátrico, em 1890.

\section{REFERÊNCIAS}

1. Peres, MAA, Barreira, IA. Desenvolvimento da assistência médica e de enfermagem aos doentes mentais no Brasil: os discursos fundadores do hospício. Texto Contexto Enferm. 2009 Out-Dez; 18(4):635-42. 
2. Padilha MICS, Sobral VRS, Leite LMR, Peres MAA, Araújo AC. Enfermeira: a construção de um modelo de comportamento a partir dos discursos médicos do início do século. Rev Latino-am Enferm. 1997; 5(1):25-33.

3. Peres MAAP. A ordem no hospício: primórdios da enfermagem psiquiátrica no Brasil (1852-1890) [tese]. Rio de Janeiro (RJ): Universidade Federal do Rio de Janeiro, Escola de Enfermagem Anna Nery, Programa de Pós-Graduação em Enfermagem; 2008.

4. Kantorski LP, Souza J, Willrich JQ, Mielke FB, Pinho LB. Saberes e estudos teóricos em enfermagem psiquiátrica e saúde mental. Rev Gaúcha Enferm. 2004 Dez; 25(3):408-19.

5. Machado R, Loureiro A, Luz R, Muricy K. Danação da norma: medicina social e constituição da psiquiatria no Brasil. Rio de Janeiro (RJ): Graal; 1978.

6. Costa R, Souza SS, Ramos FRS, Padilha MICS. Foucault e sua utilização como referencial na produção científica em enfermagem. Texto Contexto Enferm. 2006 Out-Dez; 17(4):629-37.

7. Russo JA. Psiquiatria, manicômio e cidadania no Brasil. In: Silva Filho JF, Russo JA, organizadores. Duzentos anos de psiquiatria. Rio de Janeiro (RJ): Relume-Dumará; 1993.

8. Andrade N. Carta ao provedor da Santa Casa de Misericórdia, Exm. Sr. Conselheiro Visconde de Jaguary, 9 de abril de 1882. In: A Santa Casa de Misericórdia e o Hospício de Pedro II. Rio de Janeiro: Villeneuve; 1882.

9. Foucault, M. Vigiar e punir. Nascimento da prisão. Petrópolis (RJ): Vozes; 2005.

10. Santa Casa de Misericórdia do Rio de Janeiro. Actas e Termos das sessões e deliberações da administração da Santa Casa de Misericórdia do Rio de Janeiro 1881-1890. Rio de Janeiro: Typografia do Jornal do Commércio de Rodrigues C.A; [data desconhecida].
11. Foucault M. Arqueologia do saber. $6^{\text {a }}$ ed. Rio de Janeiro (RJ): Forense Universitária; 2007.

12. Foucault, M. Microfísica do poder. Rio de Janeiro (RJ): Graal; 2003.

13. Escola Anatômica, Cirúrgica e Médica do Rio de Janeiro. In: COC/Fiocruz. Dicionário HistóricoBiográfico das Ciências da Saúde no Brasil (18321930). Rio de Janeiro (RJ); [data desconhecida] [acesso 2010 Abr 28]. Disponível em: http:/ / www. dichistoriasaude.coc.fiocruz.br/ iah/P/verbetes/ escancimerj.htm\#ficha.

14. Foucault M. Resumo dos cursos do Collège de France. Rio de Janeiro (RJ): Jorge Zahar; 1997.

15. Faculdade de medicina. Jornal do Commércio, 1883 Abr 11; Gazetilha.

16. Eiras MJF. Questões sociais: a nova cadeira de psychiatria - Hospício de Pedro II - organização de novos asylos de alienados e uma legislação apropriada. Parte I, II, III, IV, V. Jornal do Commércio, 1883 Fev 17, 18, 21, 23 Mar 1; Publicações a Pedido.

17. Campos JF. Cadeira de Clínica Psiquiátrica da Faculdade de Medicina. Jornal do Commércio, 1883 Fev 25; Publicações a Pedido.

18. Brasil. Faculdade de Medicina. Jornal do Commércio, 1883 Abr 12; Publicações a Pedido.

19. Porco em pé. Faculdade de Medicina. Jornal do Commércio, 1883 Abr 13; Publicações a Pedido.

20. A Justiça. Concurso de Psichiatria-A S.M. O Imperador. Jornal do Commércio, 1883 Abr 17; Publicações a Pedido.

21. Santa Casa de Misericórdia do Rio de Janeiro. Portarias e Atos do Provedor (1884-1890). Livro 253.

22. Portocarrero V. Arquivos da loucura: Juliano Moreira e a descontinuidade histórica da psiquiatria. Rio de Janeiro (RJ): Fiocruz; 2002. 